\title{
Human adenovirus infection of 53 children in Jilin Province of China: the clinical and bronchoscopic features
}

\section{Qiao Qian ( $\sim$ 382206212@qq.com )}

Jilin University First Hospital https://orcid.org/0000-0002-9329-3783

\section{Chunyan Li}

The First Hospital of Jilin University

\section{Fanzheng PhD Meng}

the First Hospital of Jilin University

Yuhan Ma

the First Hospital of Jilin University

Meiying Piao

the First Hospital of Jilin University

\section{Liying Wang}

The First Hospital of Jilin University

\section{Ying Wang}

The First Hospital of Jilin University

\section{Research article}

Keywords: Human Adenovirus, pneumonia, electronic bronchoscope, Children

Posted Date: July 19th, 2019

DOI: https://doi.org/10.21203/rs.2.11736/v1

License: (a) This work is licensed under a Creative Commons Attribution 4.0 International License. Read Full License 


\section{Abstract}

Abstract Background: Human adenoviruses (HAdV) has many kinds of serotypes, of which type 7 can cause severe respiratory disease, especially pneumonia. From Oct 1 st to Jan 31 st a little outbreak of this type occured in Jilin province of China and led to quite severe pneumonia, therefore we did this retrospective study to summarize the clinical and bronchoscopic features in order to help pediatric physicians get better view of the infection. Methods: Nasopharyngeal swabs or bronchoalveolar lavage fluid (BALF) were collected from pediatric patients who were diagnosed with pneumonia in our department of the First hospital of Jilin University from Oct 1st 2018 to Jan 31 st 2019. Then use immunofluorescence method (detect the nasopharyngeal swabs) or the next-generation sequencing technology (detect the BALF) to clarify the pathogen. Results: 53 children were confirmed to be infected with the HAdV, the mean age of infected children was 39.5(39.5 $\pm 25.09 \rrbracket$ months, $56.6 \%$ were less than 36 months. The ratio rate between male and female was 1.3:1. Co-infection was quite common (75\%), and happened in older group $(p=.018)$. Bronchoscope was performed on 37 children, $45.9 \%(n=17)$ had microsputum-bolt in the small distal airway or in the BALF. With the help of the next-generation sequence technology, 11 were confirmed infected with HAdV-7. We followed up the patients for 6 months, 12 by CT and 41 by telephone call. In the CT follow-up group, 8 had "Mosaic sign" on lung CT, and 4 shows mild uneven ventilation. In telephone follow-up group 31 recovered well and had no symptoms, 10 had cough and tachypnea after moderate level of daily activities. Conclusion: A) Compared with previous data in our hospital, in the winter this year, a little outbreak happened in Jilin province of China. B) We infer that HadV-7 may be the prevalent strain. C) Before we get accurate etiology diagnosis, combining with the clinical symptoms, accessory results, the micro-sputum-bolt seen in the BALF when doing the electronic bronchoscope can give us some hints of HAdV infection.

\section{Background}

Human adenovirus (HAdV) are non-enveloped viruses containing double-stranded linear DNA [1], which were first isolated in 1953 as respiratory pathogens[2, 3]. They belong to the family Adenoviridae, genus Mastadenovirus and are categorized into seven species (AG) according to their biophysical, biochemical, and genetic characteristics[4]. To date, 90 genotypes have been cognized[5]. Among these species, species B (HAdV-B3 and HAdV-B7) are usually associated with respiratory diseases[6]. Moreover, respiratory infections due to HAdV cause significant morbidity and mortality, with case fatality rates as high as 12\%[7].

Many outbreaks of acute respiratory infection caused by HAdV have been reported during the last decade in many countries including China[8-17]. Such outbreaks were also reported in the community and in military and police camps between 2011 and 2013, in 
Taiwan, Singapore, China and Malaysia [18-22]. From Oct 1st 2018 to Jan 31st 2019 a little outbreak of HAdV happened in Jilin province of China. As the severity and prevalence of such kind of infection, we did the retrospective study.

\section{Methods}

\section{Study Design}

This is a retrospective study, and focus on the inpartment patients who got to our department from Oct $1^{\text {st }}$ to Jan $31^{\text {st }}$. The following Information were collected: A) Demographic data; B) Clinical data; c) Images of lung CT and electronic bronchoscope.

\section{Inclusion criteria}

Children who were under 16-year-old diagnosed with pneumonia from Oct 1st 2018 to Jan 31st 2019 in our department meeting the following conditions would be included: A) Nasopharyngeal swabs results were HadV positive; B) Using the-generation-sequence technology to detect the BALF and confirmed the HadV infection.

\section{Virus Detection}

1. Direct immunofluorescence (DIF): Nasopharyngeal swabs, collecting from the patients after the admission, were sent to the lab and use Seven Respiratory Viruses Kit (Diagnostic Hybrids America) to detect. The kit can detect following viruses: influenza A virus, influenza B virus, Parainfluenza virus type1,2and3, respiratory syncytial virus (RSV) and Human Adenovirus (HAdV). In our study, 42 swabs were tested by this method.

2. The next-generation-sequence technology (NGS): For those we highly suspect to be coinfected (such as long duration of fever, high temperature and general status was bad), and the patients' parents agreed to do the examination used the NGS to

detect the pathogens. We reserved the BALF and ask a company ("BGI" the 
company's name) to test the sample. The technology can detect thousands of

pathogens including bacteria, fungus, virus and other untypical pathogens. Above

all we can get the genotype of the virus, which make up for the defect of the DIF.

In the study, 11 BALFs were tested by this method.

\section{Statistical method}

The data collected were analyzed by SPSS 22.0 version. Continuous variables were presented as the mean values and standard deviations (SDs), categorical variables were presented as percentages. Continuous data were analyzed by two-sided Student's t-test, when ensuring the data were normally distributed or using a two-sided Wilcoxon's ranksum test if the data were non-normal. For categorical data, group comparisons were performed by using a contingency table analysis with a $\chi^{2}$ or Fisher's exact test when appropriate. All analyses were two tailed, and p-values of 0.05 or less were considered to be statistically significant.

\section{Results}

\section{A) Epidemical features}

In our study, the oldest of the infected children was 108 months, while the youngest was 9 months, mean age was 39.5 months (39.5 \pm 25$)$. Pre-school children (36-72 months) were 16(30.2\%). Toddler period children (12-35 months) were 23(43.4\%). More than 6 months and younger than 12 months were $7(13.2 \%)$. Ratio rate between boys and girls is 1.3:1. Most of the children came from city (Table 1). According to the last 9-year data (Table 2) it shows the outbreak of HadV this winter in Jilin province of china.

\section{BᄆClinical characteristics}

Among the 53 children, 30 were in poor general condition at admission, 2 were drowsy, 30 were refused to eat or dehydrate, and 37 were dyspnea. Among which 28 were given oxygen by mask, 7 were given continuous positive airways pressure $\square \mathrm{CPAP}, 2$ were given mechanical ventilation. 53 had cough, 20 had wheezing, 3 had abdominal distension, and 8 


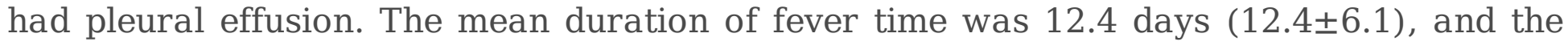
mean maximum temperature during fever was $40.1^{\circ} \mathrm{C}(40.1 \pm 0.6)$.(Table 3 )

According to the diagnostic criteria of the British Thoracic Society, the American Pediatric Infectious Diseases Society (PIDS)and the Chinese Medical Association on severe pneumonia in children, 30 of the 53 cases were diagnosed as severe pneumonia. There were 3 cases of severe pneumonia complicated with toxic encephalopathy, 3 cases of electrolyte disturbance, 2 cases of thrush, and 2 cases of anemia.

\section{CロEtiological characteristics}

Eleven of the 53 children (20.7\%) were diagnosed with human adenovirus type 7 infection by testing the BALF with the NGS technology.

The incidence of co-infection was $75 \%$ and it was more likely to occur in older children $(\mathrm{p}=0.018)$ (Table 4) (we defined co-infection as :(a) Other pathogens detected by seven respiratory virus antigens;(2) Other pathogens detected by second-generation sequencing; (3)Serum mycoplasma pneumoniae(MP) antibody $\geq 1: 160$, or double serum antibody was 4 times higher or lower; (4)Chlamydia pneumoniae(CP) antibody $>1 \mathrm{~S} / \mathrm{CO}$;(5) Clearly visible fungal infection of the mouth or vulva;(6) Others: no clear pathogenic evidence was found, but the procalcitonin (PCT) over $1.0 \mathrm{ng} / \mathrm{ml}$ would also consider the bacterial infection).Among all kinds of co-infection pathogens, MP was the most common in 18 cases, followed by CP and RSV in 5 cases, others are listed in Table 5.

\section{DᄆCell-mediated immunity}

We detected the number of immune cells (including the absolute cell counts of $\mathrm{CD} 3+\mathrm{T} / \mathrm{CD} 4+\mathrm{T} / \mathrm{CD} 8+\mathrm{T} / \mathrm{CD} 19+\mathrm{B})$ in 28 children by flow cytometry. The results showed that the absolute counts of $\mathrm{CD} 3+\mathrm{T}$ cells and $\mathrm{CD} 19+\mathrm{B}$ cells were less than the lower limit of the reference range in $50 \%$ of children, and the absolute counts of CD4+T cells were less than the lower limit of the reference range in $64.3 \%$ of children (Table 6).

\section{E) Changes under electronic bronchoscope}

Electronic bronchoscopy, as a diagnostic and therapeutic procedure, plays an important role in children's respiratory diseases. According to expert consensus on interventional diagnosis and treatment of respiratory endoscopy for refractory pneumonia in children in China, children who meet one of the following conditions will be recommended for this examination :A) Electronic bronchoscope is feasible for accurate pathogen diagnosis in the case of poor efficacy and unknown pathogen after routine treatment and detection, and suspected infection of special pathogens co-infection or drug-resistant bacteria. B) 133 
Obvious symptoms and signs of airway obstruction (such as decreased or disappeared breath sounds, tubular breathing sounds, fixed wheeze repeatedly, hypoxia and increased carbon dioxide, which are difficult to solve with conventional treatment. C) Imaging suggested that unilateral emphysema, mediastinal emphysema, unilateral or bilateral pulmonary consolidation caused by atelectasis and airway obstruction, especially small airway lesions such as disappearance of air bronchogram and tree bud sign in consolidation, could be intervened. D) Ventilator treatment presented significantly increased peak pressure, decreased tidal volume, poor oxygenation and spasmodic sputum aspiration cannot be relieved. E) mycoplasma pneumoniae, adenovirus, influenza virus and other infections are easy to cause damage to the airway mucosa, and there are many secretions, forming mucous bolts to block the airway, which is likely to cause occlusive bronchitis in the future[23].

Finally, a total of 37 infected children were examined by bronchoscopy, and 17 of them had tiny sputum bolts in small distal airways (subsegments and branches) or in alveolar lavage fluid (Picture A and Picture B). While for children not infected with $149 \mathrm{HAdV}, 86$ cases ( the total number was 835) were observed with tiny sputum bolts in bronchoscopy or alveolar lavage fluid at the same time. In conclusion, the specificity of diagnosing adenovirus infection with tiny sputum bolts in bronchoscopy or alveolar lavage fluid was 45.9\%. The incidence of tiny sputum bolts between HAdV group and non-HAdV group had statistical importance $(\mathrm{p}=0.000)$. Besides, changes may be more complex with co-infection, such as longitudinal folds of mucous membranes and/or changes in granule proliferation when combined with MP and CP (Picture C and D).

\section{F) Treatment}

In terms of drug therapy, the use of IVIG in severe group can reduce the fever days which had no statistically significant difference with the non-IVIG in mild group ( $p=0.907)$.

\section{G) Imaging performance and follow-up}

After admission, all the 53 cases received pulmonary CT examination, which had the following characteristics: A) Double lobes pneumonia were common, with a total of 40 cases $(75.5 \%):$ B) The lower lobe of the left lung was the most easily affected, with a total of 34 cases $(64.2 \%)$; C) There were 31 cases (58.5\%) of eccentric mass and ground glass changes. In addition, there were 8 cases with pleural effusion (all with a small amount of unilateral pleural effusion), among which 6 cases were left pleural effusion. We followed up the patients for 6 months, 12 by CT and 41 by telephone call. In the CT follow-up group, 8 had "Mosaic sign" on lung CT (Picture E and F), and 4 shows mild uneven ventilation. In telephone follow-up group 31 recovered well and had no symptoms, 10 had cough and tachypnea after moderate level of daily activities. 


\section{Discussion}

According to our study, 86.7\% of children younger than 6 years old are infected, which is similar to previous studies [13, 24-27], and mainly concentrated between 6 months and 36 months, which may be because children in this age group will contact more people and led to a higher risk of infection. Children less than 6 months, however, infection in our study did not find, according to previous studies, this may be because the age children with a mother who give the antibodies against adenovirus have immunity [7, 28-31]. At the same time, we found that adenovirus infections are more likely to occur in boys, men and women in our study sex ratio of 1.3:1, similar to the Gray GC data such as[22].

Based on our and previous studies, HAdV infection occurs all year round, but the incidence is higher in winter and spring[7, 30,31], while in southern China, adenovirus infection is usually high in summer[32].We have the following hypotheses for the small outbreak of adenovirus in this winter: A) The virus may prefer a warm climate. Compared with previous years, the average temperature in northeast China this winter was higher and the precipitation was less, which may be one of the reasons for the epidemic; B) There have been few reports of adenovirus infection in northeast China in recent years, and the reduced immunity of the population to adenovirus may be the second reason for this outbreak.

In this study, 11 cases of infected children were confirmed to be infected with HAdV-7 by NGS test. Therefore, we speculated that the HAdV-7 was the epidemic strain that caused the outbreak of infection this winter.

Our study found that the incidence of co-infection was high, but there was no statistical difference in clinical data between the co-infection group and the single infection group, which was similar to previous reports[32, 33]. As for the high incidence of co-infection we consider the following aspects: A) According to our study, the cell-mediated immune ability had suppressed, because of that it's easy to get other pathogen infection; B) Nowadays, the pathogen detection methods we use are more and more advanced (for example, NGS 
mentioned earlier in this paper), making the detection rate of various pathogens significantly higher than before, thus increasing the co-infection rate; C) PCT and Creactive protein are higher in the study, which often indicate the bacterial infection and led to the widespread use of antibiotics, also had similar situation in other studies [33-35], for the immune function suppressed by HAdV children the use of antibiotics will further increase the possibility of other pathogen infection. To sum up, when encountering children who are highly suspected to be infected with HAdV, we should be more cautious about the use of antibiotics, especially when and how to use.

Electronic bronchoscopy has been widely applied in children with lung disease[36, 37]. which plays an important role in the diagnosis and treatment of diseases. When it's difficult to confirm the etiology, lower airway samples can be obtained through this examination and use newly-developing method such as the NGS to clarify pathogens. What's more the combination can guide the next step of treatment. In addition, the characteristics of airway mucosa and secretions observed under bronchoscope, combined with epidemiology, clinical features and other auxiliary examinations, can give suggestive opinions to preliminarily determine the pathogen.

In terms of treatment, there is a lack of specific antiviral drugs for HAdV infection, we mainly use IVIG to give immune support and blocking antigen. In our study, this method could make no significant difference between the febrile time of children in the severe pneumonia group and non-severe pneumonia group. As an antiviral drug, cidofovir has been reported as a treatment for HAdV infection in the United Kingdom, the United States and South Korea[38-40], but it has not been reported in China.

In the CT follow-up group, 8 children had severe sequelae after 6 months, pesented as the typical "Mosaic sign" on CT, and 4 cases presented mild uneven ventilation. In the telephone follow-up group, 31 recover well, according to their parents, these children had no symptoms. However, in the rest of the telephone follow-up group (10 children), these children had cough and/or tachypnea even after a moderate level of daily activities. A Malaysian study followed up 18 children with adenovirus pneumonia infection for 2 years, 
and the results showed that $22 \%$ had pulmonary sequelae[41], which has been confirmed by earlier studies[42, 43]. However, the follow-up time of our study is still short, and further follow-up is needed to observe the outcome and recovery.

This study has the following limitations: A) The sample size included is not large enough, which may lead to the deviation of the analysis results. B) Most of the samples have not been sequenced, so our conclusion of this year's local epidemic strains may not be accurate enough. C) We didn't collect the cell-mediated immunity data when the infected children at the recovery stage, lacking effective comparison. D) Not all clinical data were collected in this study, so the results may not reflect the reality.

\section{Conclusion}

A) Compared with previous data in our hospital, in the winter this year, a little outbreak happened in Jilin province of China. B) We 243 infer that HadV-7 may be the prevalent strain. C) Before we get accurate etiology diagnosis, combining with the clinical symptoms, accessory results, the micro-sputum-bolt seen in the BALF when doing the electronic bronchoscope can give us some hints of HAdV infection.

\section{Abbreviations}

HAdV: Human Adenovirus; BALF: Bronchoalveolar lavage fluid; CT: Computed tomography; IVIG: Intravenous immunoglobulin; DIF: Direct immunofluorescence RSV: Respiratory syncytial virus; NGS: Next-generation sequence; CPAP: Continuous positive airways pressure; MP: Mycoplasma Pneumoniae; CP: Chlamydia pneumoniae; PCT: Procalcitonin.

\section{Declarations}

\section{Ethics statement}

The study protocol was approved by the Ethical Review Committee of the First Hospital of Jilin University. All the samples and information we collected were authorized by the children's parents. 
Consent for publication

Written consent to publish this case report and any accompanying images has been obtained from the patient's parents.

\section{Availability of data and materials}

The datasets used and analysed during the current study are available from the corresponding author on reasonable request.

\section{Competing interests}

Not applicable

\section{Funding}

Not applicable

\section{Authors' contributions}

QQ, FM, CL came up the initial idea and collected the clinical data. MP, YM analyzed and interpreted the patient data. All authors read and approved the final manuscript.

\section{Acknowledgements}

We thank the help Liying Wang and Ying Wang, staff of Pediatric research institute of the First Hospital of Jilin University, had offered during the data collection in out study.

\section{References}

1. James L, Vernon MO, Jones RC, Stewart A, Lu X, Zollar LM, Chudoba M, Westercamp M, Alcasid G, Duffee-Kerr $L$ et al: Outbreak of human adenovirus type 3 infection in a pediatric long-term care facility-Illinois, 2005. Clinical infectious diseases : an official publication of the Infectious Diseases Society of America 2007, 45(4):416-420.

2. Rowe WP, Huebner RJ, Gilmore LK, Parrott RH, Ward TG: Isolation of a cytopathogenic agent from human adenoids undergoing spontaneous degeneration in tissue culture. Proceedings of the Society for Experimental Biology and Medicine Society for Experimental Biology and Medicine (New York, NY) 1953, 84(3):570-573. 
3. Hilleman MR, Werner $\mathrm{JH}$ : Recovery of new agent from patients with acute respiratory illness. Proceedings of the Society for Experimental Biology and Medicine Society for Experimental Biology and Medicine (New York, NY) 1954, 85(1):183-188.

4. Esposito S, Zampiero A, Bianchini S, Mori A, Scala A, Tagliabue C, Sciarrabba CS, Fossali E, Piralla A, Principi N: Epidemiology and Clinical Characteristics of Respiratory Infections Due to Adenovirus in Children Living in Milan, Italy, during 2013 and 2014. PloS one 2016, 11(4):e0152375.

5. Group HAW (2017 [http://hadvwg.gmu.edu]

6. Lion T: Adenovirus infections in immunocompetent and immunocompromised patients. Clinical microbiology reviews 2014, 27(3):441-462.

7. Hong JY, Lee HJ, Piedra PA, Choi EH, Park KH, Koh YY, Kim WS: Lower respiratory tract infections due to adenovirus in hospitalized Korean children: epidemiology, clinical features, and prognosis. Clinical infectious diseases : an official publication of the Infectious Diseases Society of America 2001, 32(10):1423-1429.

8. Tang L, Wang L, Tan X, Xu W: Adenovirus serotype 7 associated with a severe lower respiratory tract disease outbreak in infants in Shaanxi Province, China. Virology journal 2011, 8:23.

9. Abd-Jamil J, Teoh BT, Hassan EH, Roslan N, Abubakar S: Molecular identification of adenovirus causing respiratory tract infection in pediatric patients at the University of Malaya Medical Center. BMC pediatrics 2010, 10:46.

10. Sun B, He H, Wang Z, Qu J, Li X, Ban C, Wan J, Cao B, Tong Z, Wang C: Emergent severe acute respiratory distress syndrome caused by adenovirus type 55 in immunocompetent adults in 2013: a prospective observational study. Critical care (London, England) 2014, 18(4):456.

11. Outbreak of adenovirus 14 respiratory illness-Prince of Wales Island, Alaska, 2008. MMWR Morbidity and mortality weekly report 2010, 59(1):6-10.

12. Hage E, Huzly D, Ganzenmueller T, Beck R, Schulz TF, Heim A: A human adenovirus species B subtype 21a associated with severe pneumonia. The Journal of infection 2014, 69(5):490-499.

13. Tabain I, Ljubin-Sternak S, Cepin-Bogovic J, Markovinovic L, Knezovic I, Mlinaric-Galinovic G: Adenovirus respiratory infections in hospitalized children: clinical findings in relation to species and serotypes. The Pediatric infectious disease journal 2012, 31(7):680-684.

14. Lu MP, Ma LY, Zheng Q, Dong LL, Chen ZM: Clinical characteristics of adenovirus associated lower respiratory tract infection in children. World journal of pediatrics : WJP 2013, 9(4):346-349.

15. Lee J, Choi EH, Lee HJ: Comprehensive serotyping and epidemiology of human adenovirus isolated from the respiratory tract of Korean children over 17 consecutive years (1991-2007). Journal of medical virology 2010, 82(4):624-631.

16. Abbas KZ, Lombos E, Duvvuri VR, Olsha R, Higgins RR, Gubbay JB: Temporal changes in respiratory adenovirus serotypes circulating in the greater Toronto area, Ontario, during December 2008 to April 2010. Virology journal 2013, 10:15.

17. Barrero PR, Valinotto LE, Tittarelli E, Mistchenko AS: Molecular typing of adenoviruses in pediatric respiratory infections in Buenos Aires, Argentina (1999-2010). Journal of clinical virology : the official 
publication of the Pan American Society for Clinical Virology 2012, 53(2):145-150.

18. Foong Ng K, Kee Tan K, Hong Ng B, Nair P, Ying Gan W: Epidemiology of adenovirus respiratory infections among hospitalized children in Seremban, Malaysia. Transactions of the Royal Society of Tropical Medicine and Hygiene 2015, 109(7):433-439.

19. Ng OT, Thoon KC, Chua HY, Tan NW, Chong CY, Tee NW, Lin RT, Cui L, Venkatachalam I, Tambyah PA et al: Severe Pediatric Adenovirus 7 Disease in Singapore Linked to Recent Outbreaks across Asia. Emerging infectious diseases 2015, 21(7):1192-1196.

20. Tsou TP, Tan BF, Chang HY, Chen WC, Huang YP, Lai CY, Chao YN, Wei SH, Hung MN, Hsu LC et al: Community outbreak of adenovirus, Taiwan, 2011. Emerging infectious diseases 2012, 18(11):18251832.

21. Yu P, Ma C, Nawaz M, Han L, Zhang J, Du Q, Zhang L, Feng Q, Wang J, Xu J: Outbreak of acute respiratory disease caused by human adenovirus type 7 in a military training camp in Shaanxi, China. Microbiology and immunology 2013, 57(8):553-560.

22. Yusof MA, Rashid TR, Thayan R, Othman KA, Hasan NA, Adnan N, Saat Z: Human adenovirus type 7 outbreak in Police Training Center, Malaysia, 2011. Emerging infectious diseases 2012, 18(5):852854.

23. Lili Zhong CM, Fanzheng Meng etc: Expert consensus on interventional diagnosis and treatment of respiratory endoscopy for refractory pneumonia in children in China. Chinese Journal of Practical Pediatrics 2019, 34(6):450-451.

24. Alharbi S, Van Caeseele P, Consunji-Araneta R, Zoubeidi T, Fanella S, Souid AK, Alsuwaidi AR: Epidemiology of severe pediatric adenovirus lower respiratory tract infections in Manitoba, Canada, 1991-2005. BMC infectious diseases 2012, 12:55.

25. Qurei L, Seto D, Salah Z, Azzeh M: A molecular epidemiology survey of respiratory adenoviruses circulating in children residing in Southern Palestine. PloS one 2012, 7(8):e42732.

26. Ampuero JS, Ocana V, Gomez J, Gamero ME, Garcia J, Halsey ES, Laguna-Torres VA: Adenovirus respiratory tract infections in Peru. PloS one 2012, 7(10):e46898.

27. Selvaraju SB, Kovac M, Dickson LM, Kajon AE, Selvarangan R: Molecular epidemiology and clinical presentation of human adenovirus infections in Kansas City children. Journal of clinical virology : the official publication of the Pan American Society for Clinical Virology 2011, 51(2):126-131.

28. Kwon HJ, Rhie YJ, Seo WH, Jang GY, Choi BM, Lee JH, Lee CK, Kim YK: Clinical manifestations of respiratory adenoviral infection among hospitalized children in Korea. Pediatrics international: official journal of the Japan Pediatric Society 2013, 55(4):450-454.

29. Chau SK, Lee SL, Peiris MJ, Chan KH, Chan E, Wong W, Chiu SS: Adenovirus respiratory infection in hospitalized children in Hong Kong: serotype-clinical syndrome association and risk factors for lower respiratory tract infection. European journal of pediatrics 2014, 173(3):291-301.

30. Wo Y, Lu QB, Huang DD, Li XK, Guo CT, Wang HY, Zhang XA, Liu W, Cao WC: Epidemical features of HAdV-3 and HAdV-7 in pediatric pneumonia in Chongqing, China. Archives of virology 2015, 160(3):633-638. 
31. WZ ZJ: Adenovirus analysis in pediatric pneumonia of Beijing area during the year of 1964-1967 and 1974-1977. Chin J Pediatr 1980, 18:149.

32. Xie L, Zhang B, Xiao N, Zhang F, Zhao X, Liu Q, Xie Z, Gao H, Duan Z, Zhong L: Epidemiology of human adenovirus infection in children hospitalized with lower respiratory tract infections in Hunan, China. 2019, 91(3):392-400.

33. Jin Y, Zhang RF, Xie ZP, Yan KL, Gao HC, Song JR, Yuan XH, Hou YD, Duan ZJ: Prevalence of adenovirus in children with acute respiratory tract infection in Lanzhou, China. Virology journal 2013, 10:271.

34. Ferone EA, Berezin EN, Durigon GS, Finelli C, Felicio MC, Storni JG, Durigon EL, Oliveira DB: Clinical and epidemiological aspects related to the detection of adenovirus or respiratory syncytial virus in infants hospitalized for acute lower respiratory tract infection. Jornal de pediatria 2014, 90(1):42-49.

35. Lai CY, Lee CJ, Lu CY, Lee PI, Shao PL, Wu ET, Wang CC, Tan BF, Chang HY, Hsia SH et al: Adenovirus serotype 3 and 7 infection with acute respiratory failure in children in Taiwan, 2010-2011. PloS one 2013, 8(1):e53614.

36. Radhakrishnan D, Yamashita C, Gillio-Meina C, Fraser DD: Translational research in pediatrics III: bronchoalveolar lavage. Pediatrics 2014, 134(1):135-154.

37. Zhang Y, Chen Y, Chen Z, Zhou Y, Sheng Y, Xu D, Wang Y: Effects of bronchoalveolar lavage on refractory Mycoplasma pneumoniae pneumonia. Respiratory care 2014, 59(9):1433-1439.

38. Ions R, Narayanan M, Browning M, Gaillard EA, Stiefel G, Tang JW: Case presentation: persistent adenovirus B3 infections associated with bronchiolitis obliterans treated with cidofovir in a child with mosaic tetrasomy 9p. BMC infectious diseases 2018, 18(1):529.

39. Ganapathi L, Arnold A, Jones S, Patterson A, Graham D, Harper M, Levy O: Use of cidofovir in pediatric patients with adenovirus infection. F1000Research 2016, 5:758.

40. Yoon HY, Cho HH, Ryu YJ: Adenovirus pneumonia treated with Cidofovir in an immunocompetent high school senior. Respiratory medicine case reports 2019, 26:215-218.

41. Lim LM WY, de Bruyne JA, NathanAM, Kee SY, Chan YF, et al.: Epidemiology, clinical presentation and respiratory sequelae of adenovirus pneumonia in children in KualaLumpur, Malaysia. PloS one 2018, 13:10.

42. Colom AJ, Teper AM, Vollmer WM, Diette GB: Risk factors for the development of bronchiolitis obliterans in children with bronchiolitis. Thorax 2006, 61(6):503-506.

43. Smyth A: Pneumonia due to viral and atypical organisms and their sequelae. British medical bulletin 2002, 61:247-262.

\section{Tables}

Table 1 Epidemic features 


\begin{tabular}{lc}
\hline Group & number \\
\hline Gender & $30 \square 56.6 \% \square$ \\
Male & $23 \square 43.3 \% \square$ \\
Female & $1.3: 1$ \\
Ratio(male to female) & $39.5 \pm 25$ \\
Age(months) & 0 \\
$<6$ & $7 \square 13.2 \% \square$ \\
$6-12$ & $23 \square 43.4 \% \square$ \\
$12-36$ & $16 \square 30.2 \% \square$ \\
$36-72$ & $7 \square 13.2 \% \square$ \\
$72-120$ & 0 \\
$>120$ & $6 \square \square 88.7 \% \square$ \\
City & \\
\hline
\end{tabular}

Table 3 Clinical characteristics 


\begin{tabular}{|c|c|}
\hline \multicolumn{2}{|c|}{ number/mean \pm SD } \\
\hline Duration of fever $\left({ }^{\circ} \mathrm{C}\right)$ & $12.4 \pm 6.1$ \\
\hline Highest temperature $\left({ }^{\circ} \mathrm{C}\right)$ & $40.1 \pm 0.6$ \\
\hline Bad general status & 30 \\
\hline Cough & 53 \\
\hline Wheeze & 20 \\
\hline Dyspnea & 37 \\
\hline Mask oxygen inhalation & 28 \\
\hline CPAP & 7 \\
\hline Mechanical ventilation & 2 \\
\hline Abdominal distension & 3 \\
\hline Pleural effusion & 8 \\
\hline Drowsiness & 2 \\
\hline Apastia or dehydrate & 30 \\
\hline Convulsion & 3 \\
\hline Mild pneumonia & 23 \\
\hline Severe pneumonia & 30 \\
\hline Toxic encephalopathy & 3 \\
\hline Electrolyte disturbance & 3 \\
\hline Thrush & 2 \\
\hline
\end{tabular}


Table 4 Co-Infection situation

\begin{tabular}{lrr}
\hline Group & number/mean \pm SD & p value \\
\hline Co-Infection & $40(75.5 \%)$ & \\
Age of single infection(month) & $25.0 \pm 12.7$ & \\
Age of co-infection(month) & $44.3 \pm 26.4$ & $\mathrm{p}=0.015$ \\
\hline
\end{tabular}

Table 6 Function of cell-mediated immune system

\begin{tabular}{lc}
\hline Group & number/mean \pm SD \\
\hline CD3+ T cells $(/ u l)$ & $1694.0 \pm 1070.5$ \\
CD4+ T cells(/ul) & $870.8 \pm 642.6$ \\
CD8+ T cells $/ / u l)$ & $939.1 \pm 1208.3$ \\
CD19+ B cells $(/$ ul $)$ & $575.2 \pm 479.2$ \\
\hline
\end{tabular}

Reference range:CD3+ T cells(/ul):1500-3200

$$
\begin{aligned}
& \text { CD4+ T cells(/ul):1000-2100 } \\
& \text { CD8+ T cells(/ul):450-1100 } \\
& \text { CD19+ B cells(/ul):500-1200 }
\end{aligned}
$$

\section{Supplementary Files}

This is a list of supplementary files associated with this preprint. Click to download.

- pics.docx 